\title{
Fraud Patterns Classification: A study of Fraud in business Process of Indonesian Online Sales Transaction
}

\author{
Solichul Huda \\ Department of Computer Science \\ University of Dian Nuswantoro \\ Semarang, Indonesia \\ solichul.huda@dsn.dinus.ac.id \\ Vanny Martianova Yudianingtias \\ Department of Humanities \\ University of Dian Nuswantoro \\ Semarang, Indonesia \\ vannyningtias7@gmail.com
}

\author{
Aripin \\ Department of Computer Science \\ University of Dian Nuswantoro \\ Semarang, Indonesia \\ aripin@dsn.dinus.ac.id \\ Anisti \\ Department Communications Science \\ University of Bina Sarana Informatika \\ Jakarta, Indonesia \\ anisti@bsi.ac.id
}

\author{
Mohammad Farid Naufal \\ Department of computer Science \\ Department of computer science \\ Surabaya, Indonesia \\ faridnaufal@staff.ubaya.ac.id
}

\begin{abstract}
Fraud detection has become an important research topic in recent years. In online sales transaction, fraud can occur on a business process. Fraud which occurs on business process is popularly known as process-based fraud (PBF). Previous studies have proposed PBF detection on process business model, however, false decisions are still often made because of new fraud pattern in online sales transactions. False decision mostly occurs since the method cannot identify the attributes of fraud in online sales transaction. This research proposes new fraud attributes and fraud patterns in online transactions. The attributes can be identified by exploring the event logs and Standard Operating Procedure (SOP) of online sales transactions. First, this is conducted by collecting event logs and creating SOP of online sales transaction; then, performing conformance between event logs and SOP; further, discussing with fraud experts about the result of SOP deviations which have been identified; moreover, determining convention value of the SOP deviation to fuzzy value, and classifying the SOP deviation; and at last, establishing fraud attributes and fraud patterns based on classification result. The new fraud attribute and fraud patterns are expected to increase accuracy of fraud detection in online sales transaction. Based on the evaluation, this method resulted a better accuracy 0.03 than the previous one.
\end{abstract}

Keywords - Fraud, pattern, classification, standard operating procedure, attribute, deviation

\section{INTRODUCTION}

Fraud is one of the loss causes experienced by both large and small companies. Fraud became a research theme trend nowadays because it causes a decrease in organizational and corporate revenue. It is predicted that fraud causes approximately $5 \%$ loss per year of their income [1]. The loss has reached more than 7 trillion US dollars. This loss has also been experienced by companies which use online transaction.

Companies and organization may experience a decrease in their profits since the anti-fraud system which they have cannot detect various fraud modes. The companies are possibly able to detect indications of fraud if the system can work optimally. For example, SOP violations done by employees, the company then can improve employee work system to minimize fraud incidents. In some cases, the solution can be in the form of testing the suitability of business processes with the SOP to analyze transaction data using a data mining approach, while to analyze a business process approach uses process mining.

Data mining to detect fraud has been carried out by several researchers in recent years, including by using neural network algorithm [2], a self-organizing maps algorithm [3], Dempster-Shafer theory [4] and Bayesian learning algorithms, classification models [5], empirical analysis and web service collaboration [6]. On the other hand, process mining to detect fraud has also been carried out by several researchers, by such methods as association role learning [7], hybrid ARL and process mining [8], Fuzzy MADM [9] and behavior models [10].

In 2018 fraud incidence in online transactions in Indonesia has reached more than one thousand five hundred cases. In online sales transactions, fraud detection method in [10] only obtained $85 \%$ accuracy. In contrast, in other objects, the method obtained $98 \%$ accuracy. This decreased accuracy may due to the fact that fraud attribute cannot investigate all SOP violations in online sales transactions. Thus, a fraud detection method is proposed in this paper based on SOP irregularities/deviations in online sales transactions. The identified SOP violations are defined as fraud attributes. In addition, this paper will investigate SOP violations in online sales transaction. Furthermore, the authors will also classify fraud patterns which occur and determine SOP violations weight. At last, the authors will determine whether SOP violation is categorized as fraud or not. The authors hypothesize that fraud pattern and the indicator or attribute of fraud proposed by this study are able to detect fraud in online sales transactions more accurately.

This paper is organized into seven sections. The first section elaborates the background of the study. The second section explains the research which has been previously done. Then, the third section describes identification of process mining and fraud detection. Fourth section explains case studies in this research. Section five describes the method proposes to detect fraud. Section six and section seven, contain the conclusions of the study and subsequent research which will be conducted.

\section{RELATED WORKS}

Fraud detection is considerably important to reduce the loss of company revenue caused by fraud. In online sales 
transactions, this loss could be reduced by methods which may identify fraud before the payment process. This can be done by analyzing business process in online transactions. Process mining with several methods including performance, event sequence, control flow and role analysis possesses the ability to analyze business processes. In addition, fraud detection by process mining, merging data mining and process mining has been widely used in previous studies to detect fraud.

The research [11] has proposed process mining for fraud mitigation. The studies used performance analysis, control flow analysis, and role analysis to investigate business processes. These methods have proven that process mining can detect fraud in business processes. However, those researches have not used an algorithm to detect fraud.

The concept of $1+5+1$ used a tool to detect fraud. This " $1+5+1$ " consists of (1) $\log$ preparation $+(5)\{1\} \log$ analysis $\{2\}$ process analysis, $\{3\}$ conformance analysis, $\{4\}$ performance analysis, $\{5\}$ social analysis using filters, summarization, sorting, joining and aging $+\{1\}$ iteration and refocusing. The study concluded that process mining can detect fraud in some business process models. However, this research has not yet resulted in fraud forms and fraud determination was subjectively conducted by the experts [12].

In a research [8], a combination of ARL algorithm and process mining method was proposed to detect fraud. In this study, ARL algorithm was used to identify the behavior of fraud perpetrators, while process mining was used to investigate SOP violations. This method generated rules and expert opinion for compliance checking with ARL. The study considered the weight of attributes, which were determined subjectively in deciding fraud.

Huda in [9] proposed a fuzzy approach to detect process mining based fraud. This method proposes a new attribute to detect fraud. This study conducted weighting violations and measured importance weighting on fraud attributes. Moreover, this study could investigate minor violations. However, fraud attributes offered in this study have not yet identified the originator's behavior.

A study conducted by [10] introduced behavioral models for fraud detection. The model was obtained by weighting the originator's behavior in running events and calculating the weight of the relation between the originators during the transaction. This method increased the accuracy of 0.02 to detect fraud in credit applications. However, this method only produced 0.85 accuracy to detect fraud in online transaction.

This research was conducted in Indonesia by using the event logs of some medium and small enterprises which serve online sales transactions. We obtained the logs from 3 (three) companies located in Surabaya, Yogyakarta and Jakarta. The event logs obtained were in the form of MXML format, thus it could be directly processed without doing any prior conversion.

Furthermore, the data of the event logs were normalized. This normalization was carried out to identify any redundant and incomplete data. Any identified data damage or double data were deleted to gain valid and reliable data. Then, the business process model of the online sales transactions were identified using ProM application. This business process model resulted from the ProM application was used as the basis of arranging the Standard Operating System (SOP). This study used WoPeD application for producing PNML file format to create the SOP. Moreover, the identification of fraud attributes in online sales transactions in this study was done by comparing the event logs and the SOP. A business process which violates the SOP was identified as suspicious Fraud.

\section{Process Mining AND Fraud Detection}

\section{A. Process Mining}

Process mining is a discipline focusing on extracting information from the event logs. Event logs are data about the processes carried out in a business process [13]. From these event $\log s$, information about case ID, activity name, resource, start time stamp and complete time stamp will be obtained [14]. Besides, the event log data can be developed according to the necessary information.

Trace or business processes or instances are sets of execution sequences of events $\sigma \in \mathrm{E}$ where each event is only one trace for $1 \leq i \leq j \leq|\sigma|: \sigma(i) \neq \sigma(j)$. In the trace, case code is usually defined, which is in the form of concepts and values. Furthermore, in a minimum event, concept, lifecycle, timestamp, activity and resource are defined. Resource or originator is the name of the executor who runs the event. Whereas the start and end times of running an event are indicated by the timestamp start and timestamps complete.

\section{B. Standard Operating Procedure (SOP)}

Online sales SOP consists of several data, i.e. flow, event name, and standard time of running the event The channel consists of several symbols, such as xor split, xor joint and or. The SOP can be written in various formats. Transition symbol indicates an event or operation (xor and etc), and place which describes the previous and subsequent transitions. In SOP arrangement, this research arranged SOP based on event logs using heuristic algorithms and ProM applications. Pro Mini application is able to create SOP in PNML format. Thus, this research can perform conformance event logs with SOP.

\section{Process-Mining For Fraud Detection}

There are three types of process mining: discovery, conformance, and enhancement (refinement) [15], [14]. Conformance method is used to investigate business process violations with SOPs [8], [9]. This research also uses conformance method by comparing business processes in the event $\operatorname{logs}$ with SOP. Then, the attribute values and importance weight of the attribute are determined based on the identified SOP violations.

Process-based Fraud (PBF) is fraud which occurs in a business process [9]. Detecting PBF in business process can be conducted in three different angles; from the perspective of business process, the role of the business, and from the perspective of the organization. This research detects fraud from the perspective of business processes. There are several advantages in using process mining to detect PBF. One of those is conformance checking that can be used to compare business processes with their SOPs. Another advantage of this method is the order in business processes 
can be analyzed, and fraud in online sales transactions can be detected before the payment process is done.

\section{Proposed Fraud Indicators / Attributes}

Conformance method is used to analyze business process compared to SOP. Business process which violates SOP is identified as attribute or indicator of fraud. This study identified six types of SOP violations in the event logs of online sales transactions. This identification was obtained by analyzing event data training logs. The six types of deviations consisted of short throughput time, long throughput time, distance events, different patterns, wrong decisions and parallel events. Then by using formula 1 , four of the six attributes were determined as fraud indicators or attributes. These four attributes were short throughput time, long throughput time, distance events, and different patterns. In addition, wrong decision attribute and parallel events are not categorized as fraud attributes since they did not have a significant stream of fraud events. The desciption of each SOP deviation is shown in Table 1.

$$
r=\frac{\mathrm{n}\left(\sum X Y\right)-\left(\sum X\right)\left(\sum Y\right)}{\sqrt{\left[n\left(\sum X^{2}\right)-\left(\sum X\right)^{2}\right]\left[n\left(\sum Y^{2}\right)-\left(\sum Y\right)^{2}\right.}}
$$

Where $r$ is the value of the correlation coefficient, $X$ is observation of variable $\mathrm{X}, \mathrm{Y}$ is observation of variable $\mathrm{Y}, \mathrm{n}$ is the pair's number of observations $\mathrm{Y}$ and $\mathrm{X}$.

TABLE I. DESCRIPTION OF PBF ATTRIBUTES

\begin{tabular}{|c|c|c|c|}
\hline Attribute & Description & \multicolumn{2}{|c|}{ Example } \\
\hline \multirow[t]{3}{*}{$\begin{array}{l}\text { Throughput } \\
\text { time short }\end{array}$} & \multirow{3}{*}{$\begin{array}{l}\text { The event } \\
\text { execution time } \\
\text { is shorter than } \\
\text { low time } \\
\text { tolerance }\end{array}$} & Event name & $\begin{array}{l}\text { Standard } \\
\text { time }\end{array}$ \\
\hline & & Input order & 15 minutes \\
\hline & & \multicolumn{2}{|c|}{$\begin{array}{c}\text { Execution of "input order" event } \\
\text { takes only } 8 \text { minutes instead of } 15 \\
\text { minutes }\end{array}$} \\
\hline $\begin{array}{l}\text { Throughput } \\
\text { time long }\end{array}$ & $\begin{array}{l}\text { The event } \\
\text { execution time } \\
\text { is longer than } \\
\text { upper time } \\
\text { tolerance }\end{array}$ & \multicolumn{2}{|c|}{$\begin{array}{l}\text { Execution of "input order" event } \\
\text { takes } 35 \text { minutes }\end{array}$} \\
\hline $\begin{array}{l}\text { Different } \\
\text { pattern }\end{array}$ & $\begin{array}{l}\text { A case pattern } \\
\text { is different from } \\
\text { that of the } \\
\text { business } \\
\text { process in SOP }\end{array}$ & \multicolumn{2}{|c|}{$\begin{array}{c}\mathrm{D}-\mathrm{E}-\mathrm{F} \\
\text { business process pattern } \\
\mathrm{D}-\mathrm{F}-\mathrm{E} \\
\text { Case pattern }\end{array}$} \\
\hline Distant events & $\begin{array}{l}\text { The distance } \\
\text { between one } \\
\text { event and the } \\
\text { following event } \\
\text { is longer than } \\
\text { the standard } \\
\text { time for } \\
\text { executing the } \\
\text { two events }\end{array}$ & \multicolumn{2}{|c|}{$\begin{array}{l}\text { Distance time execution of "See } \\
\text { Item" and "Select Item" is more } \\
\text { than time of standard events } \\
\text { distance }\end{array}$} \\
\hline
\end{tabular}


analysis; of which distance events analysis method is proposed in this study.

Conformance which is performed on event logs and SOP is able to identify various indicators or attributes of fraud in some cases. In conducting conformance, this study applied throughput time analysis method, different pattern analysis, distant event analysis and skip analysis. After conducting conformance on event logs, there were 5 SOP violation identified, i.e. throughput time short (short throughput time), throughput time long (long throughput time), different pattern, distanct event and skip. For instance, case code C00008 was identified as Throughput Time Long one dan different pattern one; case code C00229 was identified as Throughput Time Short two dan Throughput Time Long one, and so on. Table 2 shows the examples of identified SOP violation.

TABLE II. EXAMPLE OF SOP VIOLATION

\begin{tabular}{|c|c|c|c|c|c|}
\hline $\begin{array}{l}\text { Case } \\
\text { Code }\end{array}$ & 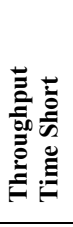 & 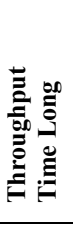 & 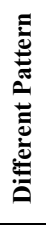 & 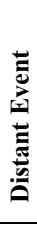 & $\frac{\vec{n}}{\omega}$ \\
\hline $\mathrm{C} 00008$ & & 1 & 1 & & \\
\hline $\mathrm{C} 00042$ & 2 & & & & \\
\hline $\mathrm{C} 00101$ & & & & 1 & \\
\hline C00229 & 2 & 1 & & & \\
\hline $\mathrm{C} 00232$ & & 1 & & & \\
\hline $\mathrm{C} 00285$ & & & & 1 & \\
\hline C00298 & 1 & & & 1 & \\
\hline
\end{tabular}

Moreover, the number of each identified attribute violations is converted into attribute value in the form of fuzzy numbers with low, middle and high membership. Form of fuzzy numbers with low, middle and high membership. The function of fuzzy membership is the same as in study [9]. Case code C0008 has throughput time long low and different pattern low. Code C00229 has throughput time short middle and throughput time long low. The examples of SOP violation are presented in Table 3. In addition, the attribute values of each case are classified to illustrate the identified fraud patterns. Eq. 3 is used to classifying fraud patterns, as in [16].

TABLE III. EXAMPLE OF SOP VIOLATION IN FUZZY

\begin{tabular}{|c|c|c|c|c|c|}
\hline Case Code & 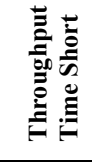 & 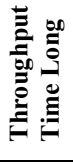 & 总 & 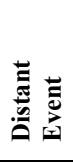 & $\frac{\hat{n}}{\tilde{n}}$ \\
\hline $\mathrm{C} 00008$ & & Low & Low & & \\
\hline $\mathrm{C} 00042$ & Middle & & & & \\
\hline $\mathrm{C} 00101$ & & & & Low & \\
\hline C00229 & Middle & Low & & & \\
\hline $\mathrm{C} 00232$ & & Low & & & \\
\hline
\end{tabular}

\begin{tabular}{|l|l|l|l|l|l|} 
C00285 & & & & Low & \\
\hline C00298 & Low & & & Low & \\
\hline
\end{tabular}

$d\left(x_{i}+x_{j}\right)=\sqrt{\sum_{r=1}^{n}\left(a_{r}\left(x_{i}\right)-\left(a_{r}\left(x_{j}\right)^{2}\right.\right.}$

Where $d\left(x_{i}+x_{j}\right)$ is eucledean distance, $x_{i}$ is record $\mathrm{i}, x_{j}$ is record $\mathrm{j}, a_{r}$ is date $\mathrm{r}$ and $\mathrm{i}, \mathrm{j}$ are $1,2,3 \ldots$ ets.

$\mathrm{KNN}$ algorithm is used to obtained shorten of distance value between data in training data. $\mathrm{KNN}$ algorithm is presented in Eq. 4, as in [17].

$$
d_{n n}\left(x_{1}, x_{2}\right)=\min _{1 \leq i \leq r, 1 \leq j \leq r} d\left(y_{i}, z_{j}\right)
$$

This study was expected to classify the business process or any case violating the SOP. This classification would obtain the pattern of SOP violation from all existing business process in event logs. Code F001 is for throughput time short Low and different pattern Low. Code F002 means throughput time long Low and distant event Low. Finally, the expert assigns fraud weight to each fraud pattern. Fraud code F001 is given 10\% weight, while F002 is given $20 \%$ weight. This fraud pattern weighing was conducted based on the experience of fraud experts. The examples of fraud patterns and fraud weights for each pattern are shown respectively in Table 4 and Table 5.

\section{B. Fraud Detection in Online Sales Transaction Business Process}

In a case or a process instance will end with a payment. Before carrying out the payment process, this detection method is done first. For example, there is an identified SOP violation in that case; accordingly, convert the violation into the attribute value. Based on fraud attribute, search for a table of fraud patterns, such as:

Find Throughput time short $=$ low and event distance $=$ middle

Then, fraud code "F007" pattern with 35\% fraud weight will be obtained. To determine whether the case is fraud or not, compare fraud weight with threshold fraud value. This research found 0,45 threshold value. Thus, it can be determined that the case is not fraud or categorized as minor violation. However, if the fraud weight is above 0.45 , this study confirms that the occuring SOP violations are included in fraud category.

TABlE IV. Fraud Pattern in Online Sales Transaction

\begin{tabular}{|l|r|r|r|r|r|}
\hline & & & & \\
$\begin{array}{l}\text { Fraud } \\
\text { Code }\end{array}$ & Low & & Low & & \\
\hline F001 & Low & & Low & \\
\hline F002 & & Low & Low & \\
\hline F003 & & & & Low & \\
\hline F004 & Middle & & & & \\
\hline
\end{tabular}




\begin{tabular}{|c|c|c|c|c|c|} 
F005 & & Middle & & & \\
\hline F006 & & & & Low & High \\
\hline F007 & Low & & & Middle & \\
\hline
\end{tabular}

TABLE V. Fraud Pattern AND Fraud Weights

\begin{tabular}{|c|c|c|c|c|c|c|}
\hline 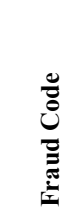 & 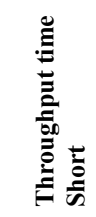 & 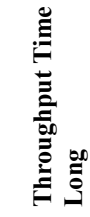 & 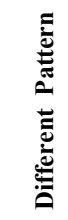 & 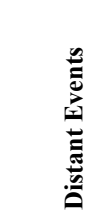 & $\frac{\bar{v}}{\omega}$ & $\underset{E}{\mathbb{E}}$ \\
\hline F001 & Low & & Low & & & $10 \%$ \\
\hline F002 & & Low & & Low & & $20 \%$ \\
\hline F003 & & & & Low & & $10 \%$ \\
\hline F004 & Middle & & & & & $5 \%$ \\
\hline F005 & & Middle & & & & $30 \%$ \\
\hline F006 & & & & Low & High & $90 \%$ \\
\hline F007 & Low & & & Middle & & $35 \%$ \\
\hline
\end{tabular}

\section{Experimental Result and Discussion}

This research applied two methods of fraud analysis, the method proposed by in [8] and the method used in this study. These two methods were implemented to obtain the benefits of the proposed method. Moreover, evaluation process consists of two scenarios: (1) analyzing test data using internal methods [8], and (2) analyzing test data using methods proposed in this study. Then, the experts analyzed test data using their own methods. Accuracy evaluation of both methods was used to find out the benefits of the methods. In addition, Eq. (5) was used to calculate the accuracy of the methods.

Accuracy $=\frac{T P+T N}{T P+T N+F P+F N}$

This research used fuzzy approach to investigate SOP violations as a fraud or not. Furthermore, this fuzzy approach was also used in the evaluation stage to analyze test data.

Receiver operating characteristics (ROC) was used to measure the accuracy of fraud detection method. Such accuracy measurement was conducted by concerning on true positive (TP), true negative (TN), false positive (FP), and false negative $(\mathrm{FN})$. TP was used to state that the experts and the method resulted in a similar conclusion of a case as a fraud. Meanwhile, TN is used to refer to the fact that the experts and this method resulted in the same statement that a case in not a fraud. On the other hand, when the experts defined a case as a fraud and the method concluded not as a fraud, it belonged to FN. Besides, when the experts stated that a case was not a fraud, instead the method stated that the case was not a fraud, then it can be categorized as FP.

TABLE VI. REsult of Test Data Evaluation

\begin{tabular}{|l|l|l|}
\hline Method & ROC variable & Accuracy \\
\hline
\end{tabular}

\begin{tabular}{|l|l|l|l|l|l|}
\hline & \multicolumn{1}{|c|}{$T P$} & $F P$ & $F N$ & \multicolumn{1}{|c|}{$T N$} & \\
\hline $\begin{array}{l}\text { Previous } \\
\text { method }\end{array}$ & 229 & 0 & 593 & 3178 & 0.85 \\
\hline $\begin{array}{l}\text { The } \\
\text { proposed } \\
\text { method }\end{array}$ & 352 & 0 & 470 & 3178 & 0.88 \\
\hline
\end{tabular}

Evaluation on test data resulted in 822 cases of SOP violation. The results of the experts' discussion showed that the method in [8] resulted that 229 cases were identified as true positive, 593 cases as false positive, and 3178 cases as true negative. Meanwhile, by using this method, 352 cases were identified as true positive, 470 cases as false positive, and 3178 cases as true negative. The use of Eq. (5), the method in [8] resulted 0.85 accuracy, while the proposed method obtained 0.88 accuracy. The summary of the test data evaluation can be seen in the following Table 6 .

\section{CONCLUSION}

This study identified 5 fraud attributes in online sales transactions. Those fraud attributes are throughput time long, throughput time short, distant event, different patterns and skip. The findings of fraud attributes could increase the accuracy of fraud detection in online sales transactions. In addition, this study also identified 52 fraud patterns in online sales transactions. At initial investigation, the determination of SOP violation as fraud or not referred to the fraud patterns of which the weight was subjectively determined by the experts. Hence, the determination of fraud weight is significant for the accuracy in fraud detection. This study could identify new forms of SOP violation, i.e. distant event. This attribute has made the proposed method resulted better accuracy.

\section{SUGGESTION}

This study is an initial research to detect fraud in online sales transactions. Future research shall conduct weighting attribute values, importance of attribute weight and determining fraud rating. The study is conducted in order to make fraud weighting can be automatically done by the system.

\section{REFERENCES}

[1] E. W. T. Ngai, Y. Hu, Y. H. Wong, Y. Chen, and X. Sun, "The Application of Data Mining Techniques in Financial Fraud Detection: A Classification framework and an Academic Review of Literature". Decision Support Systems, Vol. 50, No. 3, pp. 559-569, 2010.

[2] D. R. Kalyani and D. U. Devi, "Fraud Detection of Credit Payment System by Genetic Algorithm", International Journal of Scientific \& Engineering Research, vol. 3, no. 7, (2012), pp. 1-6.

[3] V. Zaslavsky and A. Strizhak, "Credit Card Fraud Detection Using Self-Organizing Maps”, Information \& Security, vol. 18, (2006), pp. 48-63.

[4] S. Panigrahi, A. Kundu, S. Sural, and A.K. Majumdar, "Credit Card Fraud Detection: A Fusion Approach Using Dempster-Shafer Theory and Bayesian Learning", Information Fusion, vol. 10, no. 4, (2009), pp. 354-363.

[5] A. Shen, R. Tong and Y. Deng, "Application of Classification Models on Credit Card Fraud Detection", Proceedings of 2007 International Conference on Service System and Service Management, IEEE, Chengdu, China,( 2007) June 9-11.

[6] A. Shen, R. Tong and Y. Deng, "Application of Classification Models on Credit Card Fraud Detection", Proceedings of 2007 International Conference on Service System and Service Management, IEEE, Chengdu, China,( 2007) June 9-11.

[7] S. Huda, R. Sarno, T. Ahmad, H. A. Santosa, "Identification of Process-based Fraud Paterns in Credit Application", 2 nd 
International Conference on Information and Communication Technology (ICoICT), (2014) June 28-29.

[8] R. Sarno, D. R. Dewandono, T. Ahmad, M. F. Naufal and F. Sinaga, "Hybrid Association Rule Learning and Process Mining for Fraud Detection", IAENG International Journal of Computer Science, vol. 42, no. 2, (2015), pp. 59-72.

[9] S. Huda, R. Sarno and T. Ahmad, "Fuzzy MADM approach for Rating of Process-based Fraud", Journal ICT. Research Application, vol. 9, no. 2, (2016), pp. 111-128.

[10] S. Huda, R. Sarno and T. Ahmad, "Increasing Accuracy of Processbased Fraud Detection Using A Behavior Model", International Journal of Software engineering and its application, vol. 9, no. 2, (2015), pp. 111-128

[11] M. Jans, M. J. van der Werf, N. Lybaert and K. Vanhoof, "A Business Process Mining Application for Internal Transaction Fraud Mitigation", Expert Systems with Applications, vol. 38, no. 10, (2011), pp. 13351-13359.

[12] J. J. Stoop, "Process Mining and Fraud Detection", Thesis, Business Information Technology Department, Twente University, Enschede, Netherlands, 2012
[13] R. Sarno, P. L. I. Sari, H. Ginardi, D. Sunaryono , I. Mukhlash, "Decision Mining For Multi Choice Workflow Patterns", International conference on Computer, Control, and Its Application, (2013) November 19-21.

[14] W. M. P. van der Aalst, "Discovery, Conformance and Enhancement of Business Processes", Springer, pp. 7-8, (2010).

[15] W. M. P. van der Aalst and A. K. A. de Medeiros, "Process Mining and Security: Detecting Anomalous Process Executions and Checking Process Conformance", Electronic Notes in Theoretical Computer Science, vol. 121, (2005), pp. 3-21.

[16] J. Han and M. Kamber, Data Mining : Concept and Techniques. New York, Morgan Kaufmann Publisher, 2006.

[17] G. Goujon, Chaoqun, and W. Jianhong, Data Clustering :Theory, Algorithms, and Applications. Virginia, ASA, 2007. 
Institutional Sign In

\section{Quick Links}

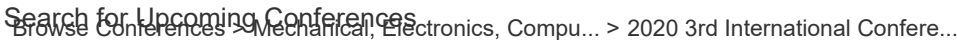
IEEE Publication Recommender

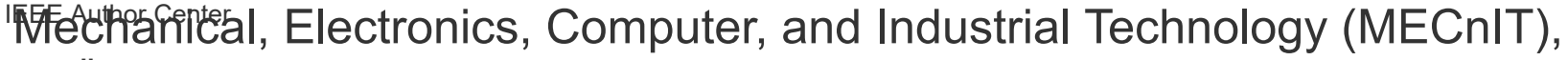 Proceedings

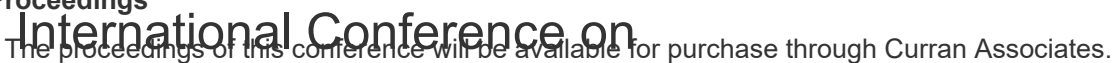

\begin{tabular}{ll} 
Refine & $\checkmark$ \\
\hline Author & $\checkmark$ \\
\hline Affiliation & $\checkmark$ \\
\hline $\begin{array}{l}\text { Conference } \\
\text { Location }\end{array}$ & $\checkmark$
\end{tabular}

\section{Quick Links}

Search for Upcoming Conferences IEEE Publication Recommender IEEE Author Center

\section{Proceedings}

The proceedings of this conference will be available for purchase through Curran Associates.

Mechanical, Electronics, Computer, and Industrial Technology (MECnIT), 2020 3rd International Conference on
Analysis of Critical Success Factors on ERP Implementation in PT. Toyota Astra Motor Using Extended Information System Success Model

Safira Aini; Muharman Lubis; R. Wahjoe Witjaksono; Anik Hanifatul Azizah

Publication Year: 2020 , Page(s): 370 - 375

Cited by: Papers (1)
Abstract
(637 Kb)

Analysis of Critical Success Factors on ERP Implementation in PT. Toyota Astra Motor Using Extended Information System Success Model

Safira Aini; Muharman Lubis; R. Wahjoe Witjaksono; Anik Hanifatul Azizah

2020 3rd International Conference on Mechanical, Electronics,

Computer, and Industrial Technology (MECnIT)

Year: 2020

Search Query Clustering Comparation On E-Commerce Using KMeans And Adaptive DBSCAN

Darwin; Ronsen Purba; Muhammad Fermi Pasha

Publication Year: 2020 , Page(s): 207 - 211

$$
\text { Abstract (945 Kb) }
$$

Search Query Clustering Comparation On E-

Commerce Using K-Means And Adaptive DBSCAN

Darwin; Ronsen Purba; Muhammad Fermi Pasha

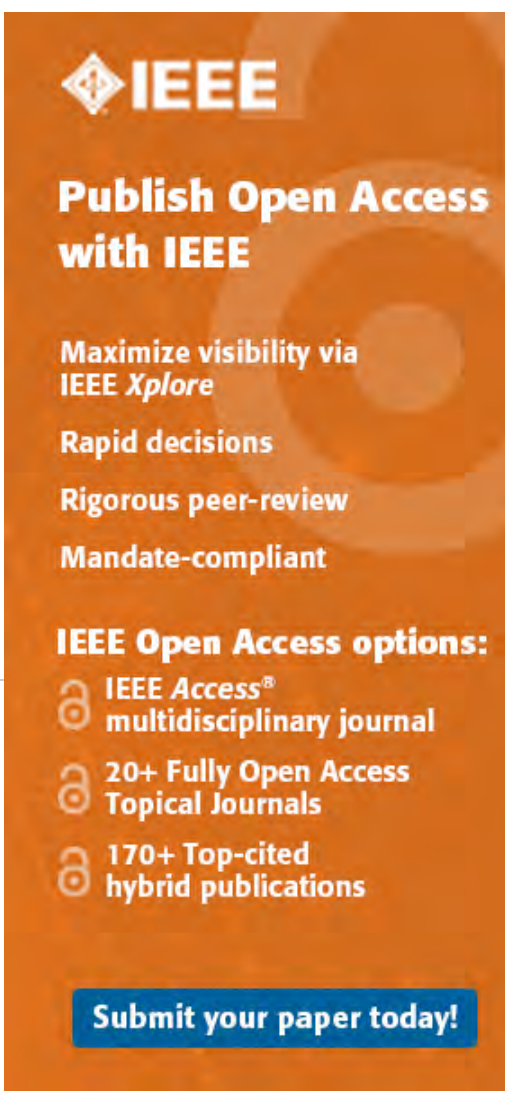


Print on

Demand Purchase at

Partner
2020 3rd International Conference on Mechanical, Electronics, Computer, and Industrial Technology (MECnIT)

Year: 2020

The Object Detection on Video Transmission over Wireless Visual Sensor Network

Kalvein Rantelobo; Hendro F. J. Lami; Andreas C.

Louk; Bernandus; Nyoman P. Sastra

Publication Year: 2020 , Page(s): 54 - 57
Abstract
$(1029 \mathrm{~Kb})$

The Object Detection on Video Transmission over Wireless Visual Sensor Network

Kalvein Rantelobo; Hendro F. J. Lami; Andreas C.

Louk; Bernandus; Nyoman P. Sastra

2020 3rd International Conference on Mechanical, Electronics,

Computer, and Industrial Technology (MECnIT)

Year: 2020

EMG Based Control of a Quadcopter

Maham Ali; Areeba Riaz; Waleef Ullah Usmani; Noman Naseer

Publication Year: 2020 , Page(s): 250 - 254
Abstract
$(756 \mathrm{~Kb})$

EMG Based Control of a Quadcopter

Maham Ali; Areeba Riaz; Waleef Ullah Usmani; Noman Naseer 2020 3rd International Conference on Mechanical, Electronics, Computer, and Industrial Technology (MECnIT)

Year: 2020

Characterizing the Effect of Motion Class Taxonomy on the Performance of Hand Motion Classifiers

Waseem Shahzad; Yasar Ayaz; Muhammad Jawad Khan; Noman Naseer; Amad Zafar

Publication Year: 2020 , Page(s): 58 - 63

Abstract

$(1765 \mathrm{~Kb})$

Characterizing the Effect of Motion Class Taxonomy on the Performance of Hand Motion Classifiers

Waseem Shahzad; Yasar Ayaz; Muhammad Jawad Khan; Noman Naseer; Amad Zafar

2020 3rd International Conference on Mechanical, Electronics,

Computer, and Industrial Technology (MECnIT)

Year: 2020

Control of Two-Link Robot Manipulator with Uncertainty Parameter using Self-Tuning Sliding Mode Control Anisa Ulya Darajat; Swadexi Istiqphara

Publication Year: 2020 , Page(s): 376 - 380

Abstract

$(1016 \mathrm{~Kb})$

Control of Two-Link Robot Manipulator with Uncertainty Parameter using Self-Tuning Sliding Mode Control

Anisa Ulya Darajat; Swadexi Istiqphara 2020 3rd International Conference on Mechanical, Electronics, Computer, and Industrial Technology (MECnIT) Year: 2020

Fraud Patterns Classification: A study of Fraud in business Process of Indonesian Online Sales Transaction Solichul Huda; Aripin; Mohammad Farid Naufal; Vanny Martianova Yudianingtias; Anisti

Publication Year: 2020 , Page(s): 212 - 217
Abstract
$(988 \mathrm{~Kb})$

Fraud Patterns Classification: A study of Fraud in 
business Process of Indonesian Online Sales

Transaction

Solichul Huda; Aripin; Mohammad Farid Naufal; Vanny Martianova

Yudianingtias; Anisti

2020 3rd International Conference on Mechanical, Electronics,

Computer, and Industrial Technology (MECnIT)

Year: 2020

Study of UAV Application in Wireless Sensor Networks

Fan Zhang; Huidan Liu; Ziqian Ma; Yi Yang; Xuefen Wan

Publication Year: 2020 , Page(s): 343 - 348

Abstract

$(1592 \mathrm{~Kb})$

Study of UAV Application in Wireless Sensor

Networks

Fan Zhang; Huidan Liu; Ziqian Ma; Yi Yang; Xuefen Wan 2020 3rd International Conference on Mechanical, Electronics, Computer, and Industrial Technology (MECnIT)

Year: 2020

The Effect of Bicubic Interpolation on Viola-Jones and Principal Component Analysis in Detecting Faces and Helmet Wearers Hasanal Fachri Satia Simbolon; Sawaluddin; Pahala Sirait Publication Year: 2020 , Page(s): 158 - 164

Abstract

$(1350 \mathrm{~Kb})$

The Effect of Bicubic Interpolation on Viola-Jones and Principal Component Analysis in Detecting Faces and Helmet Wearers

Hasanal Fachri Satia Simbolon; Sawaluddin; Pahala Sirait 2020 3rd International Conference on Mechanical, Electronics, Computer, and Industrial Technology (MECnIT)

Year: 2020

\section{Analysis of Certainty Factor Methods to Determine Skills in} Generation $Y$

Hasanul Fahmi; Adli A Nababan; Miftahul Jannah; Mufida

Khairani; Yessy F A Lubis; Syahrul Fahri

Publication Year: 2020 , Page(s): 222 - 225

Abstract

(758 Kb)

Analysis of Certainty Factor Methods to Determine Skills in Generation Y

Hasanul Fahmi; Adli A Nababan; Miftahul Jannah; Mufida

Khairani; Yessy F A Lubis; Syahrul Fahri

2020 3rd International Conference on Mechanical, Electronics,

Computer, and Industrial Technology (MECnIT)

Year: 2020

Hybrid of Support Vector Machine Algorithm and K-Nearest Neighbor Algorithm to Optimize the Diagnosis of Eye Disease

Sumita Wardani; Sawaluddin; Poltak Sihombing

Publication Year: 2020 , Page(s): 321 - 326
Abstract
$(2076 \mathrm{~Kb})$

Hybrid of Support Vector Machine Algorithm and KNearest Neighbor Algorithm to Optimize the Diagnosis of Eye Disease

Sumita Wardani; Sawaluddin; Poltak Sihombing 2020 3rd International Conference on Mechanical, Electronics, Computer, and Industrial Technology (MECnIT)

Year: 2020

Feature Selection on K-Nearest Neighbor Algorithm Using Similarity Measure

Ratih Puspadini; Herman Mawengkang; Syahril Efendi 
Publication Year: 2020 , Page(s): 226 - 231

Abstract (1134 Kb)

Feature Selection on K-Nearest Neighbor Algorithm

Using Similarity Measure

Ratih Puspadini; Herman Mawengkang; Syahril Efendi

2020 3rd International Conference on Mechanical, Electronics,

Computer, and Industrial Technology (MECnIT)

Year: 2020

Ultrasonic Sensor Assessment for Obstacle Avoidance in Quadcopter-based Drone System

Suherman Suherman; Rizky Ananda Putra; Maksum Pinem

Publication Year: 2020 , Page(s): 50 - 53

$$
\text { Abstract (1132 Kb) }
$$

Ultrasonic Sensor Assessment for Obstacle Avoidance in Quadcopter-based Drone System

Suherman Suherman; Rizky Ananda Putra; Maksum Pinem 2020 3rd International Conference on Mechanical, Electronics, Computer, and Industrial Technology (MECnIT)

Year: 2020

The Extended Internet of Thing Node Impact to Data Collection Performances

Suherman Suherman; Fahmi; Zul Herri

Publication Year: 2020 , Page(s): 46 - 49
Abstract
$(569 \mathrm{~Kb})$

$\square \quad$ The Extended Internet of Thing Node Impact to Data

\section{Collection Performances}

Suherman Suherman; Fahmi; Zul Herri

2020 3rd International Conference on Mechanical, Electronics,

Computer, and Industrial Technology (MECnIT)

Year: 2020

Smart Rice Cooker with PID Method to Warm Food using Android Application

Ratna Aisuwarya; Yona Vidiana

Publication Year: 2020 , Page(s): 261 - 266

Cited by: Papers (1)
Abstract
$(1267 \mathrm{~Kb})$

Smart Rice Cooker with PID Method to Warm Food using Android Application

Ratna Aisuwarya; Yona Vidiana

2020 3rd International Conference on Mechanical, Electronics,

Computer, and Industrial Technology (MECnIT)

Year: 2020

Designing GaAs Based Semi-Elliptical Nano Plasmonic Coupler with Analytical Assessment

Md. Saiful Islam Sumon; Nowshed Al Nur Hridoy; Anas

Mahmood; Rakibul Hasan Sagor

Publication Year: 2020 , Page(s): 64 - 68
Abstract
$(597 \mathrm{~Kb})$

Designing GaAs Based Semi-Elliptical Nano

Plasmonic Coupler with Analytical Assessment

Md. Saiful Islam Sumon; Nowshed Al Nur Hridoy; Anas

Mahmood; Rakibul Hasan Sagor

2020 3rd International Conference on Mechanical, Electronics,

Computer, and Industrial Technology (MECnIT)

Year: 2020

Combining the Active Learning Algorithm Based on the Silhouette Coefficient with PCKmeans Algorithm 
Kartika Sari; Syahril Efendi; Sawaluddin Nasution

Publication Year: 2020 , Page(s): 232 - 237
Abstract
$(1145 \mathrm{~Kb})$

Combining the Active Learning Algorithm Based on the Silhouette Coefficient with PCKmeans Algorithm

Kartika Sari; Syahril Efendi; Sawaluddin Nasution

2020 3rd International Conference on Mechanical, Electronics,

Computer, and Industrial Technology (MECnIT)

Year: 2020

Optimization of Smooth Support Vector Machine Algorithm Using Backpropagation Nguyen Widrow Algorithm in Classification of Mellitus Diabetes Disease

Ananda Mutia Dewi; Tulus; Muhammad Zarlis

Publication Year: 2020 , Page(s): 132 - 136
Abstract
$(819 \mathrm{~Kb})$

Optimization of Smooth Support Vector Machine

Algorithm Using Backpropagation Nguyen Widrow Algorithm in Classification of Mellitus Diabetes

Disease

Ananda Mutia Dewi; Tulus; Muhammad Zarlis

2020 3rd International Conference on Mechanical, Electronics, Computer, and Industrial Technology (MECnIT)

Year: 2020

Population Initialization In Genetic Algorithm For Traveling Salesmen Problem Using Steepest Ascent Hill Climbing Algorithm

Paet Rahmadani; Muhammad Zarlis; Syahril Efendi

Publication Year: 2020 , Page(s): 238 - 242
Abstract
$(751 \mathrm{~Kb})$

Population Initialization In Genetic Algorithm For

Traveling Salesmen Problem Using Steepest Ascent

Hill Climbing Algorithm

Paet Rahmadani; Muhammad Zarlis; Syahril Efendi

2020 3rd International Conference on Mechanical, Electronics,

Computer, and Industrial Technology (MECnIT)

Year: 2020

Android based Optimization and Queue System at Passenger Vessel Services Crossings

Yonata Laia; Oloan Sihombing; Saut Parsaoran Tamba; Mardi Turnip; Volvo Sihombing; Nimron Siahaan; Robin; Arjon Turnip Publication Year: 2020 , Page(s): 327 - 331
Abstract
$(1218 \mathrm{~Kb})$

Android based Optimization and Queue System at Passenger Vessel Services Crossings

Yonata Laia; Oloan Sihombing; Saut Parsaoran Tamba; Mardi Turnip; Volvo Sihombing; Nimron Siahaan; Robin; Arjon Turnip 2020 3rd International Conference on Mechanical, Electronics, Computer, and Industrial Technology (MECnIT)

Year: 2020

Optimization of Durian Supply Chain with Dynamic System Simulation

Nurhayati Sembiring; Ryan Ivanro Polinezer Sipayung

Publication Year: 2020 , Page(s): 108 - 113
Abstract
$(1789 \mathrm{~Kb})$

Optimization of Durian Supply Chain with Dynamic System Simulation

Nurhayati Sembiring; Ryan Ivanro Polinezer Sipayung 


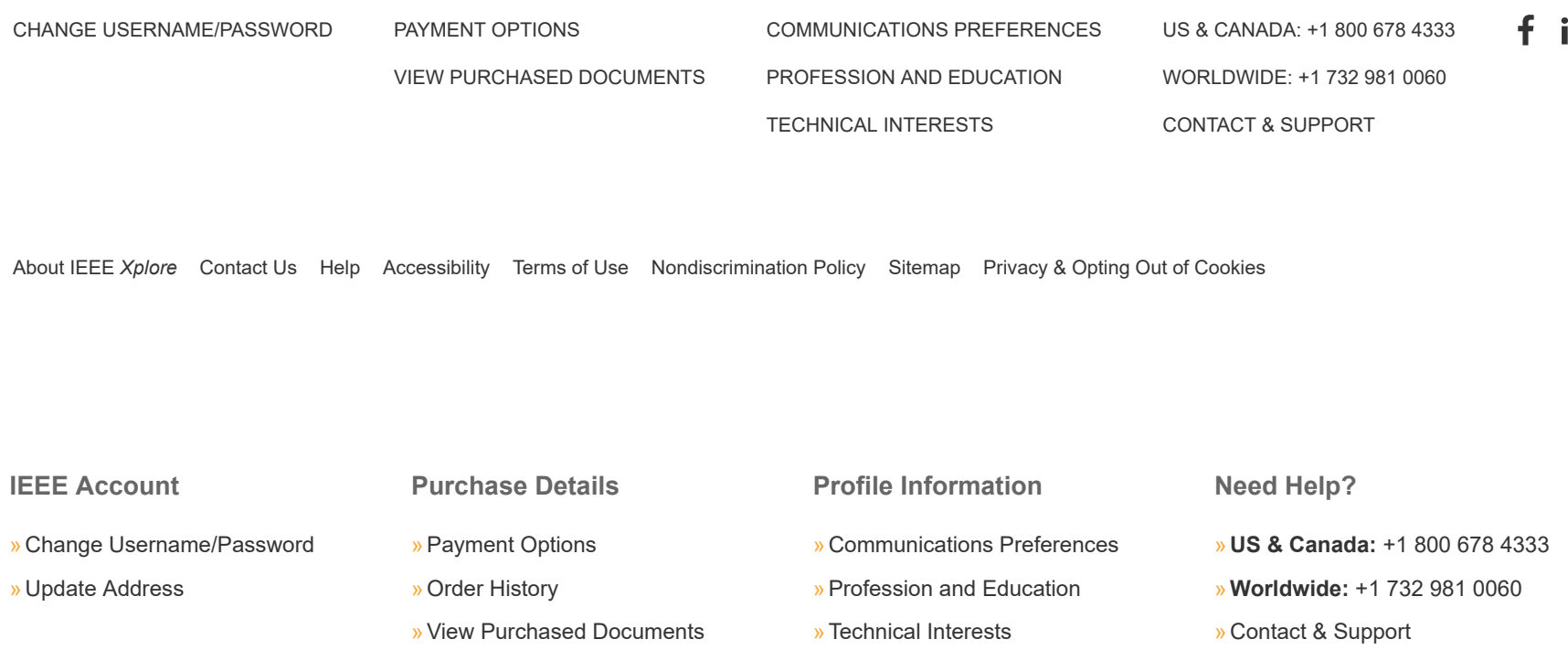

About IEEE Xplore Contact Us Help Accessibility Terms of Use Nondiscrimination Policy Sitemap Privacy \& Opting Out of Cookies 
IEEE.org IEEE Xplore IEEE-SA IEEE Spectrum More Sites SUBSCRIBE SUBSCRIBECart Create Account Personal Sign In $\Rightarrow$ J

Browse $\checkmark$ My Settings $\checkmark$ Help $\vee \quad$ Institutional Sign In

Institutional Sign In

\section{Fraud Patterns Classification: A study of Fraud in business Process of Indonesian Online Sales Transaction}

Publisher: IEEE

$$
\text { Cite This }
$$

PDF

Solichul Huda ; Aripin ; Mohammad Farid Naufal ; Vanny Martianova Yudianingtias ; Anisti
Q

ADVANCED SEARCH $\mathbf{4 6}$
Full
Text Views

Abstract

Document Sections

I. Introduction

II. Related Works

III. Process Mining and Fraud Detection

IV. Case study

V. Fraud Detection

Show Full Outline -

Authors

References

Keywords

Metrics

More Like This

PDF

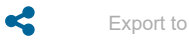

\section{Alerts}

Manage

Content Alerts

Add to Citation

Alerts access to IEEE Xplore

for your organization?

CONTACT IEEE TO SUBSCRIBE
Need

Full-Text

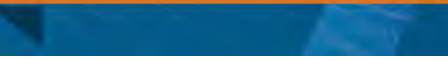

More Like This

Fuzzy Ranking of Financial Statements for Fraud Detection 2006 IEEE International Conference on Fuzzy Systems Published: 2006

Application of fuzzy set theory to evaluate the rate of aggregative risk in information security

2013 International Conference on Research and Innovation in Information Systems (ICRIIS)

Published: 2013
Abstract:Fraud detection has become an important research topic in recent years. In online sales transaction, fraud can occur on a business process. Fraud which occurs on business... View more

\section{Metadata}

Abstract:

Fraud detection has become an important research topic in recent years. In online sales transaction, fraud can occur on a business process. Fraud which occurs on business process is popularly known as process-based fraud (PBF). Previous studies have proposed PBF detection on process business model, however, false decisions are stil often made because of new fraud pattern in online sales transactions. False decision mostly occurs since the method cannot identify the attributes of fraud in online sales transaction. This research proposes new fraud attributes and fraud patterns in online transactions. The attributes can be identified by exploring the event logs and Standard Operating Procedure (SOP) of online sales transactions. First, this is conducted by collecting event logs and creating SOP of online sales transaction; then, performing conformance between event logs and SOP; further, discussing with fraud experts about the result of SOP deviations which have been identified; moreover, determining convention value of the SOP deviation to fuzzy value, and classifying the SOP deviation; and at last, establishing fraud attributes and fraud patterns based on classification result. The new fraud attribute and fraud patterns are expected to increase accuracy of fraud detection in online sales transaction. Based on the evaluation, this method resulted a better accuracy 0.03 than the previous one.

\section{IEEE Authors:}

Increase Your Research Impact

Add executable code to your research articles 
Date of Conference: $25-27$ June 2020

Date Added to IEEE Xplore: 14 August 2020

ISBN Information:
INSPEC Accession Number: 19890153

DOI: 10.1109/MECnIT48290.2020.9166644

Publisher: IEEE

Conference Location: Medan, Indonesia

No metrics found for this document.

\section{:三 Contents}

\section{Introduction}

Fraud is one of the loss causes experienced by both large and small companies. Fraud became a research theme trend nowadays because it causes a decrease in organizational and corporate revenue. It is

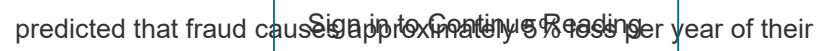
income [1]. The loss has reached more than 7 trillion US dollars. This loss has also been experienced by companies which use online transaction.

\begin{tabular}{|c|c|c|c|c|c|c|c|}
\hline \multicolumn{7}{|l|}{ Authors } & $\checkmark$ \\
\hline \multicolumn{7}{|c|}{ References } & $\checkmark$ \\
\hline \multicolumn{7}{|c|}{ Keywords } & $\checkmark$ \\
\hline \multicolumn{7}{|l|}{ Metrics } & $\widehat{\Lambda}$ \\
\hline \multicolumn{8}{|c|}{ Usage ? } \\
\hline 2021 & \multicolumn{6}{|c|}{2020} & \\
\hline Jan & Feb & Mar & Apr & May & Jun & \multirow{4}{*}{\multicolumn{2}{|c|}{$\begin{array}{l}\mathbf{4 6} \\
\text { Total usage } \\
\text { since Aug } 2020\end{array}$}} \\
\hline 2 & - & 4 & - & - & - & & \\
\hline Jul & Aug & Sep & Oct & Nov & Dec & & \\
\hline - & - & - & - & - & - & & \\
\hline
\end{tabular}

\section{Citations ?}

\section{Search for}

Citations in 